\title{
STUDIES OF RED BLOOD CELL AND SERUM POLYMORPHISMS AMONG THE MATAGI
}

\author{
Hideo Matsumoto ${ }^{1}$, Tasuku Toyomasu, ${ }^{1}$ \\ Kaoru Sagisaka, ${ }^{2}$ Kenkichi Takahashi, ${ }^{3}$ \\ and Arthur G. STEINBERG ${ }^{4}$ \\ ${ }^{1}$ Department of Legal Medicine, Osaka Medical School, Takatsuki, Osaka \\ 'Department of Legal Medicine, Gifu University School of Medicine, Gifu \\ ${ }^{3}$ Department of Forensic Medicine, Akita University School of Medicine, Akita \\ ${ }^{4}$ Department of Biology, Case Western Reserve University, Cleveland, Ohio
}

\begin{abstract}
Summary Serum samples from 159 Matagi were tested for nine blood group systems, haptoglobins, transferrins, Gc, 10 red blood cell enzyme polymorphisms and for the $\mathrm{Gm}$ and Inv allotypes to obtain evidence concerning their ethnic origin. The data exclude all claims except that they are of Japanese origin.
\end{abstract}

\section{INTRODUCTION}

The Matagi have lived in the Ohu mountains of north eastern Japan for an unknown number of centuries. They differ from the main body of Japanese in two respects; they speak a dialect (Matagi) of Japanese peculiar to them and they were and are professional big game hunters. There was and may still be an involved tradition (religion?) associated with the hunting pattern (Encyclopedia of the World). These two cultural characteristics have kept them isolated from the remainder of the inhabitants of Japan and this has led to much speculation about their origin, especially by cultural anthropologists. The speculations range from the claim by the folklorist Kita (1932) that the Matagi are Ainu to Muto's claim (1970) that they are descended from a tribe in India.

The hypotheses advanced by the cultural anthropologists concerning the origin of the Matagi are so markedly heterogeneous that one would have expected physical anthropologists to have studied them. We know of no such studies, however. While we are not physical anthropologists, it seemed to us that a study of genetic polymorphisms among these people could offer insight concerning their racial ancestry. Accordingly, several serum and red blood cell polymorphisms were determined on 159 blood samples collected from Matagi living in villages in the Ohu mountains.

Received June 13, 1977 
Table 1. Reagents used to type serum samples from the Matagi for $\mathrm{Gm}$ and Inv allotypes.

\begin{tabular}{lll}
\hline Allotype & Anti-Allotype & Anti-D \\
\hline Gm(1) & Mor & Bar \\
Gm(2) & Ham & Bar \\
Gm(3) & Coa & Car \\
Gm(5) & Pay & Jol \\
Gm(6) & Har & Kre \\
Gm(13) & Ter & Jol \\
Gm(14) & Ber & Car \\
Gm(15) & $2624^{1}$ & Pur \\
Gm(16) & George & Pur \\
Gm(17) & R 15 & Bar \\
Gm(21) & Cli & Bar \\
Gm(26) & Whi & Kre \\
Inv(1) & Mas & Roe \\
\hline
\end{tabular}

${ }^{1}$ Gift from Dr. E. van Loghem.

${ }^{2}$ Gift from Dr. M. Schanfield.

${ }^{a}$ Rhesus monkey anti-Gm(16).

${ }^{4}$ Rabbit anti-Gm(17).

\section{MATERIALS AND METHODS}

Blood samples were collected from 159 Matagi residing in the following villages: Nakamura, Shinnaka, Koyawatari, Okashinai, Hitachinai, Utto, Nekko and Totorinai in Kita-Akita County, Akita Prefecture.

Blood groups (ABO, MNSs, Rh, Kell, Duffy, Kidd, Diego, Lutheran, P), haptoglobins, transferrins, Gc, and enzyme polymorphisms (red blood cell acid phosphatase, adenosine deaminase, phosphogluconate dehydrogenase, esterase D, phosphoglucomutase, glutamic-pyruvic transaminase, glutamic-oxaloacetic transaminase, phosphohexose isomerase, phosphoglycerate kinase and adenylate kinase) were determined in Japan by standard methods (Giblett, 1969). The sera were tested in Cleveland, by previously published methods (Steinberg, 1962) for Gm $(1,2,3,5,6,13$, $14,17,21,26)$, and $\operatorname{Inv}(1)$ with the reagents shown in Table 1. Selected samples were tested for $\mathrm{Gm}(15)$ and $\mathrm{Gm}(16)$. The allotypes, except for $\mathrm{Gm}(26)$, are described in Grubb's book (1970). Gm(26) is usually present in a haplotype lacking Gm(15) and, vice versa, it is usually absent when the haplotype carries $\mathrm{Gm}(15)$ (van Loghem and Grobbelaar, 1971; Steinberg, in press.)

\section{RESULTS}

Gm and Inv: The data, analysed without regard to $\mathrm{Gm}(26)$, to make comparisons with published data easier, are presented in Table 2 (The data for $\mathrm{Gm}(26)$ will be discussed in a later section). The haplotype frequencies were estimated by the 
Table 2. Gm and Inv data for serum samples from Matagi tested for $\operatorname{Gm}(1,2,3,5,6,13,14,17,21)$.

\begin{tabular}{|c|c|c|c|c|c|}
\hline \multirow[b]{2}{*}{ Gm Phenotype } & \multicolumn{2}{|c|}{ Numbers } & \multicolumn{3}{|c|}{ Haplotypes } \\
\hline & Obs. & Exp. & $\mathrm{Gm}$ & Freq. & $\sigma$ \\
\hline $1,13,17,21$ & 39 & 42.5 & $1,17,21$ & .453 & .029 \\
\hline $1,17,21$ & 34 & 32.6 & $1,13,17$ & .295 & .025 \\
\hline $1,2,17,21$ & 27 & 27.2 & $1,2,17,21$ & .161 & .021 \\
\hline $1,2,13,17,21$ & 17 & 15.1 & $1,3,5,13,14$ & .091 & .016 \\
\hline $1,13,17$ & 15 & 13.9 & & & \\
\hline $1,3,5,13,14,17,21$ & 14 & 13.1 & & & \\
\hline $1,3,5,13,14,17$ & 8 & 8.6 & & & \\
\hline $1,2,3,5,13,14,17,21$ & 3 & 4.7 & & & \\
\hline $1,3,5,13,14$ & 2 & 1.3 & & & \\
\hline Total & 159 & 159.0 & & & \\
\hline \multicolumn{6}{|l|}{$\begin{array}{l}\chi^{2}{ }_{(5)}=1.721 \\
.9>p>.8\end{array}$} \\
\hline \multicolumn{6}{|c|}{ Inv } \\
\hline & \multicolumn{2}{|c|}{ Phenotype } & No. & & \\
\hline & \multirow{2}{*}{\multicolumn{2}{|c|}{$\begin{array}{r}1 \\
-1\end{array}$}} & 81 & & \\
\hline & & & 78 & & \\
\hline & \multicolumn{2}{|c|}{ Total } & 159 & & \\
\hline & $I n v^{1}=$ & & & & \\
\hline
\end{tabular}

maximum likelihood method assuming the Hardy-Weinberg (H.-W.) equilibrium, with the aid of the computer program MAXIM (Kurczynski and Steinberg, 1967). We are aware of nine publications reporting tests of serum samples from eleven Japanese populations for at least $\operatorname{Gm}(1,2,3,5,13)$ (Mårtensson et al., 1966; Matsumoto and Takatsuki, 1968a and b; Schanfield et al., 1972; Steinberg and Goldblum, 1965; Steinberg and Kageyama, 1970; Ueno, 1975; van Loghem and Mårtensson, 1967; van Loghem et al., 1970). The haplotype frequencies were determined for the data from these publications with the computer program MAXIM. Each of the 11 gave a satisfactory fit to the H.-W. distribution. Each population had four haplotypes and these were equivalent to haplotype $G m^{1,17,21}, G m^{1,2,17,21}, G m^{1,3,5,13,14}$, and $G m^{1,13,17}$ found when tests are done for $\operatorname{Gm}(1,2,3,5,6,13,14,17,21)$. Furthermore, the haplotype frequencies among the several samples appeared to be the same, within statistical limits. The data for the 11 samples were treated as though each had been tested for only $\mathrm{Gm}(1,2,3,5,13)$ and reanalysed, to permit a test for heterogeneity to be performed. The test gave $\chi^{2}{ }_{(20)}=9.212 ; .975>p>.950$. Clearly, the data may be considered to be homogeneous. Accordingly, the haplotype frequencies as determined for the 2,360 samples in the 11 sets of data are used for comparison with the haplotype frequencies found for the Matagi.

We know of published reports of three sets of samples from Ainu tested for Gm and Inv allotypes (Matsumoto and Miyazaki, 1972; Steinberg, 1966; Steinberg and 
Kageyama, 1970). These samples were treated as were those for the Japanese, and these also may be considered to be homogeneous $\left(\chi^{2}{ }_{(3)}=0.023 ; .9995>p>.9990\right)$. The haplotype frequencies as determined for the 753 Ainu samples in the three sets of data are used for comparison with the haplotype frequencies found for the Matagi.

The data for the Ainu, Japanese, and Matagi are presented in Table 3. All of the haplotype frequencies for the Matagi and the Japanese are the same, within statistical limits, while all of the haplotype frequencies for the Ainu, except that for $G m^{1,13,17}$, are significantly different from those for the Japanese and from those for the Matagi. As far as these data are concerned, the conclusion must be that the $\mathrm{Gm}$ patterns of the Matagi are similar to those of the Japanese with no evidence of Ainu ancestry. Similarly, the data exclude origin from India. (See Steinberg (1974) for a review of $\mathrm{Gm}$ data for India.)

The homogeneity of the haplotype frequencies among the Japanese is striking. The samples came from populations covering a range of about $1,100 \mathrm{~km}$; from the southern coast of Hokkaido on the north to Osaka on the south. Samples collected in Europe or Africa over a comparable distance show clear-cut heterogeneity (Johnson et al., 1977).

We are aware of six publications that report Inv(1) data for eight Japanese populations (Schanfield et al., 1972; Steinberg and Kageyama, 1970; Steinberg and Matsumoto, 1964; Abe, 1965; Ueno and Yokoyama, 1964; van Loghem et al., 1970). The $I n v^{1}$ allele frequencies are homogeneous, therefore we have summed all the data to arrive at a weighted mean frequency.

Three publications have data for Inv(1) for the Ainu (Matsumoto and Miyazaki, 1972; Steinberg, 1966; Steinberg and Kageyama, 1970). These data have also been combined to yield a single estimate.

Table 3. Comparison of haplotype frequencies among Ainu, Japanese and Matagi. ${ }^{1}$

\begin{tabular}{|c|c|c|c|c|c|c|c|c|c|c|c|}
\hline \multirow[t]{2}{*}{ Population No. } & \multirow[t]{2}{*}{ No. } & \multicolumn{2}{|c|}{$1,17,21$} & \multicolumn{2}{|c|}{$1,2,17,21$} & \multicolumn{2}{|c|}{$1,3,5,13,14$} & \multicolumn{2}{|c|}{$1,13,17$} & \multicolumn{2}{|c|}{$2,17,21$} \\
\hline & & Freq. & s.e. & Freq. & s.e. & Freq. & s.e. & Freq. & s.e. & Freq. & s.e. \\
\hline Ainu & 753 & .548 & .014 & .070 & .019 & .028 & .004 & .272 & .013 & .082 & .018 \\
\hline Japanese & 2360 & .472 & .008 & .164 & .006 & .102 & .005 & .262 & .007 & & \\
\hline Matagi & 159 & .453 & .029 & .161 & .021 & .091 & .016 & .295 & .025 & & \\
\hline
\end{tabular}

\footnotetext{
${ }^{1}$ See text for details.
}

Table 4. In $v^{1}$ allele frequencies among Ainu, Japanese and Matagi. ${ }^{1}$

\begin{tabular}{lrrr}
\hline Population & No. & \multicolumn{2}{c}{ Inv } \\
\cline { 3 - 4 } & & Freq. & s.e. \\
\hline Ainu & 753 & .195 & .011 \\
Japanese & 2294 & .304 & .007 \\
Matagi & 159 & .300 & .028 \\
\hline
\end{tabular}

${ }^{1}$ See text for details. 
Table 5. Gm phenotypes and probable genotypes for a Matagi family with an unusual pattern for $\mathrm{Gm}$ (26).

\begin{tabular}{lll}
\hline Individual & \multicolumn{1}{c}{ Phenotype $^{1}$} & \multicolumn{1}{c}{ Probable genotype } \\
\hline Fa. & $1,2,17,21,26$ & $1,2,17,21,26 / 1,17,26$, or 1,26, or 26 \\
Mo. & $1,13,15,16,17,21,26$ & $1,13,15,16,17 / 1,17,21,26$ \\
Proband & $1,13,15,16,17,26$ & $1,13,15,16,17 / 1,17,26$, or 1,26, or 26 \\
Sib & $1,2,17,21,26$ & $1,2,17,21,26 / 1,17,21,26$ \\
\hline
\end{tabular}

\footnotetext{
${ }^{1}$ All samples were tested for $\mathrm{Gm}(1,2,3,5,6,13,14,15,16,17,21,26)$.
}

The $I n v^{1}$ allele frequencies $(.300 \pm .28)$ is also essentially the same as those for the Japanese and significantly different from those for the Ainu (Table 4).

Gm 26: As mentioned in the MATERIALS AND METHODs section, this antigen is expected to be absent from a haplotype when $\mathrm{Gm}(15)$ is present and vice versa, it is expected to be present when $\mathrm{Gm}(15)$ is absent.

The $G m^{1,13,17}$ haplotype becomes $G m^{1,13,15,16,17}$ when tests are done for $\operatorname{Gm}(15$, 16) on serum samples from Japanese; hence those with the phenotype $\operatorname{Gm}(1,13,17)$ (i.e. $\operatorname{Gm}(1,13,15,16,17)$ and therefore homozygous for $\left.G m^{1,13,15,16,17}\right)$ are expected to be $\operatorname{Gm}(-26)$ and all others are expected to be $\operatorname{Gm}(26)$. This expectation was fulfilled in 158 of the 159 samples. The exception is in a sample from a 17 year old girl with the phenotype $\operatorname{Gm}(1,13,15,16,17,26)$. The Gm data for this donor and her family are presented in Table 5. Tests of blood samples drawn six months after the first set confirmed the results of the tests of the first samples. The proband's serum is Gm $(-21)$ when tested undiluted with two different anti-Gm(21) antisera. We conclude that the data are correct.

If $\operatorname{Gm}(26)$ had not been determined, the father's probable genotype (Table 5) would have been believed to be $G m^{1,2,17,21} / G m^{1,2,17,21}$ or $G m^{1,2,17,21} / G m^{1,17,21}$ and the proband, whose probable genotype would have been believed to be $G m^{1,13,15,16,17}$ $G m^{1,13,15,16,17}$, would have been considered to be extra-marital. None of the blood groups, serum factors (other than $\mathrm{Gm}$ ) or enzyme polymorphisms indicate paternal exclusion.

The most likely interpretation, it seems to us, is that the father and the proband have a rare haplotype that produces $\operatorname{Gm}(1,17,26)$, or $\operatorname{Gm}(1,26)$, or $\operatorname{Gm}(26)$. Unfortunately, samples from the father's relatives are not available for testing.

The Blood Group Data: The blood group data, except for S, Kell, Lu(a), Di(a), and $P_{1}$ which are not polymorphic in the population, are summarised in Tables 6A and $6 \mathrm{~B}$.

The samples were tested for ABO with anti-A and anti-B only. The fit to H.-W. expectancy is satisfactory. Unfortunately the allele frequencies for the Japanese and Ainu overlap considerably (Mourant, 1954; Mourant et al., 1976), hence this system is not of help in characterizing the Matagi.

The samples were tested with anti-M, anti- $\mathrm{N}$ and anti-S, but only three were $\mathrm{S}$ positive. Therefore the data are treated as though the samples were tested for $M$ 
Table 6A. Observed and expected phenotype numbers for the $\mathrm{ABO}$, $\mathrm{MN}, \mathrm{Rh}, \mathrm{Jk}$, and Fy blood groups among the Matagi.

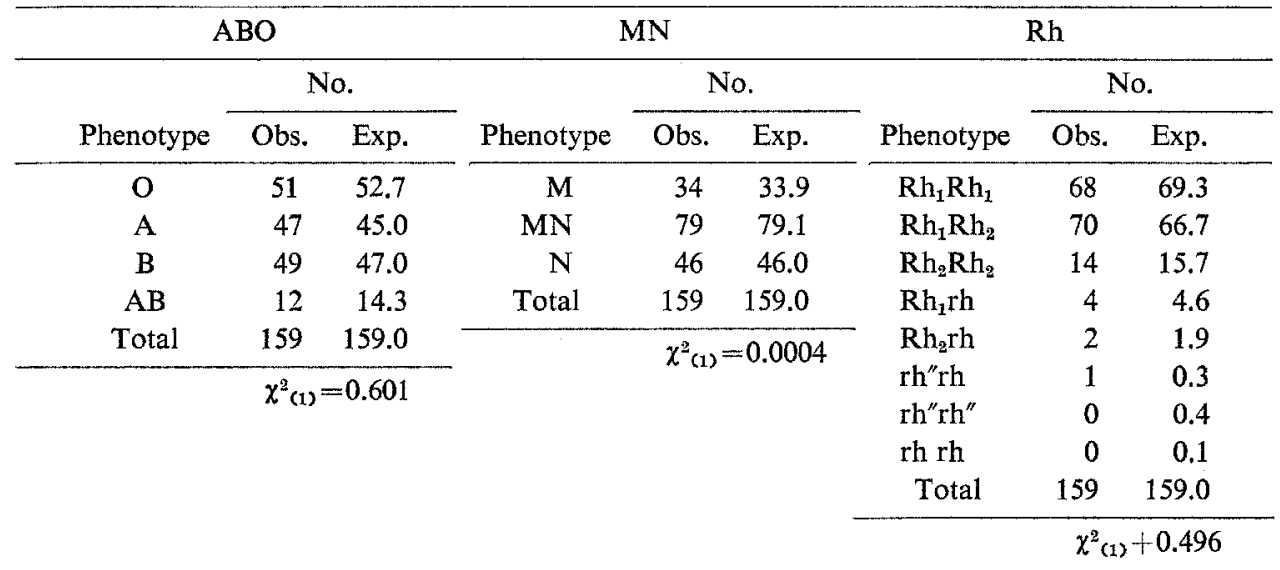

\begin{tabular}{|c|c|c|c|c|}
\hline \multicolumn{2}{|c|}{ Kidd } & \multicolumn{3}{|c|}{ Duffy } \\
\hline Phenotype & No. & \multirow[b]{2}{*}{ Phenotype } & \multicolumn{2}{|c|}{ No. } \\
\hline \multirow{6}{*}{$\begin{array}{l}\text { Jk }(\mathrm{a}+) \\
\mathbf{J k}(\mathrm{a}-) \\
\text { Total }\end{array}$} & 70 & & Obs. & Exp. \\
\hline & 88 & $\mathrm{a}$ & 134 & 130.9 \\
\hline & 158 & $a b$ & 14 & 20.3 \\
\hline & & $\mathrm{b}$ & 4 & 0.8 \\
\hline & & Total & 152 & 152.0 \\
\hline & & & $\chi^{2}(1)=$ & $=14.829$ \\
\hline
\end{tabular}

Table 6B. Frequencies of the alleles for the ABO, MN, Rh, Jk and Fy blood groups among the Matagi.

\begin{tabular}{lccl}
\hline System & Allele & Freq. & s.e. \\
\hline ABO & $I^{\mathrm{A}}$ & .208 & .024 \\
& $I^{\mathrm{B}}$ & .216 & .025 \\
& $I^{0}$ & .576 & .030 \\
$\mathrm{MN}$ & $M$ & .462 & .039 \\
$\mathrm{Rh}$ & $R^{1}$ & .660 & .027 \\
& $R^{2}$ & .270 & .042 \\
& $r$ & .022 & .008 \\
& $r^{\prime \prime}$ & .048 & .035 \\
Kidd & $J k^{\mathrm{a}}$ & .254 & .026 \\
Duffy & $F y^{\mathrm{a}}$ & .928 & .021 \\
\hline
\end{tabular}

and $\mathrm{N}$ only. The frequency of the $M$ allele $(.462$, Table $6 \mathrm{~B})$ is low for a Japanese population (frequencies $>.5$; Mourant et al., 1976) and high for an Ainu population ( .4; Mourant et al., 1976). The frequency of the $S$ allele is $\$ .15$ among the Ainu and <.10 among the Japanese (Misawa and Hayashida, 1972; Nakajima, 1961). Hence the frequency of .010 among the Matagi, while unusually low, is more like that of the Japanese than that of the Ainu. 
Table 7. Haptoglobin and $\mathrm{Gc}$ frequencies among the Matagi.

\begin{tabular}{|c|c|c|c|c|c|}
\hline \multicolumn{3}{|c|}{ Hp (omitting $2 \mathrm{Hp}-0$ ) } & \multicolumn{3}{|c|}{$\mathrm{Gc}$} \\
\hline \multirow[b]{2}{*}{ Phenotype } & \multicolumn{2}{|c|}{ No. } & \multirow[b]{2}{*}{ Phenotype } & \multicolumn{2}{|c|}{ No. } \\
\hline & Obs. & Exp. & & Obs. & Exp. \\
\hline 1 & 2 & 5.1 & 1 & 61 & 59.2 \\
\hline $2-1$ & 53 & 46.5 & $2-1$ & 72 & 75.6 \\
\hline 2 & 102 & 105.4 & 2 & 26 & 24.2 \\
\hline Total & 157 & 157.0 & Total & 159 & 159.0 \\
\hline \multicolumn{3}{|c|}{$\chi^{2}(1)=2.903$} & & \multicolumn{2}{|c|}{$\chi^{2}(1)=0.360$} \\
\hline \multicolumn{3}{|c|}{$\mathrm{Hp}^{1}=.181 \pm .031$} & \multicolumn{3}{|c|}{$\mathrm{Gc}^{1}=.610 \pm .039$} \\
\hline
\end{tabular}

Table 8. Enzyme polymorphisms among 159 samples from Matagi, Japanese.

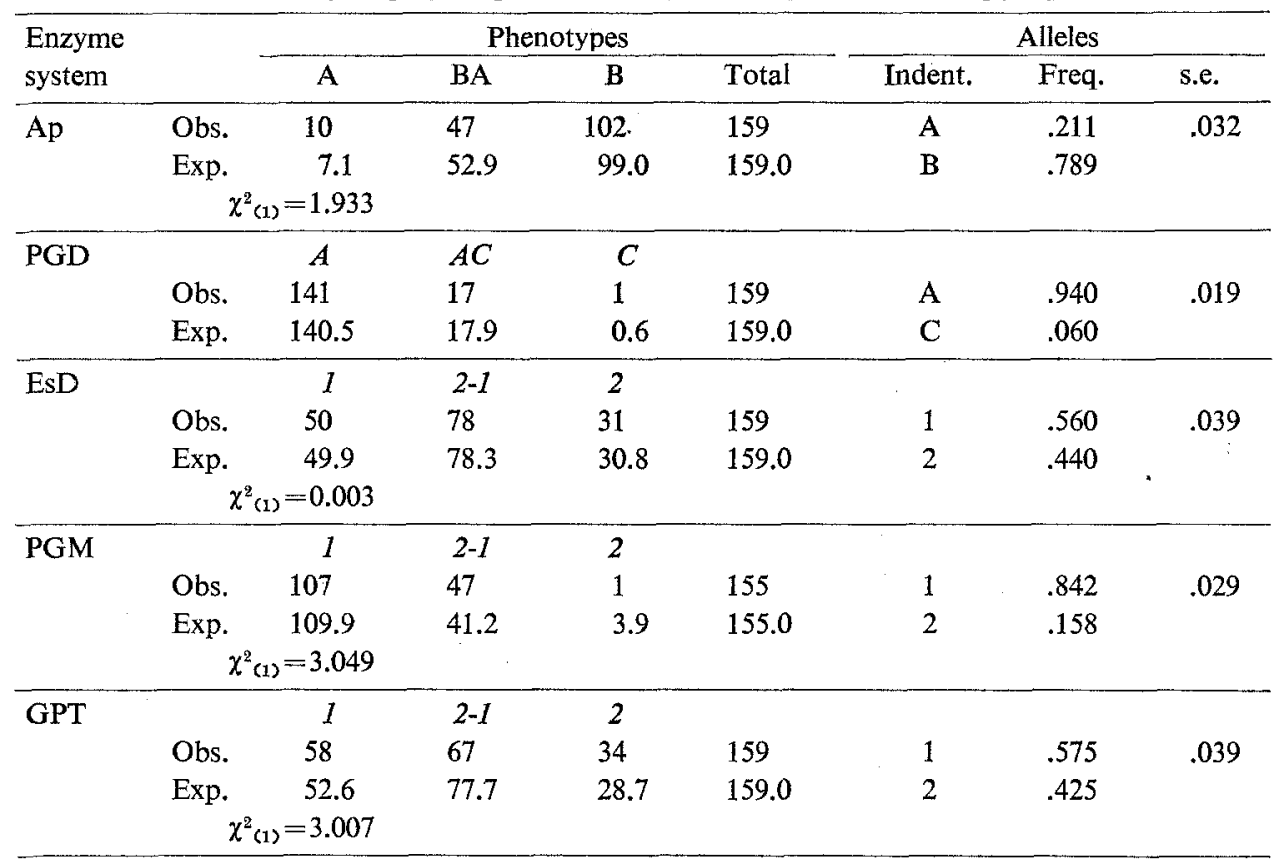

The Rh phenotypes were determined by means of anti-C, anti-D, anti-E, anti-c, and anti-e. The data are presented in Tables 6A and 6B. Here again, the allele frequencies derived for the Matagi samples are much more similar to those of the Japanese than to those of the Ainu (Mourant et al., 1976). Thus $R^{1}$ (CDe) and $R^{2}$ (cDE) are more frequent and $r^{\prime \prime}(\mathrm{cdE})$ is much less frequent among the Japanese and the Matagi than among the Ainu.

The $J k^{\mathrm{a}}$ allele frequency (Table 6B) is lower than those reported for either the Ainu ( .3) or the Japanese $(\sim .4)$ (Mourant et al., 1976), but is closer to that for the Ainu and thus contradicts the data for the blood groups reviewed thus far.

The $F y^{\mathrm{a}}$ allele frequency is very high and essentially the same for the Ainu and 
the Japanese (over .9 in both populations, Mourant et al., 1976). The .928 frequency of $F y^{2}$ among the Matagi (Table 6B) fits in with the earlier investigation of Japanese and Ainu.

The $P_{1}$ allele frequency is $\sim .15$ in both Japanese and Ainu (Mourant et al., 1976). It is .068 among the Matagi $\left(18 / 159\right.$ were $\left.P_{1}(+)\right)$, hence distinctly different from both the former populations.

$D i^{a}$ of the Diego system occurs with a frequency of less than .05 in all three populations. Seven out of 159 samples were $\mathrm{Di}(\mathrm{a}+) ; D i^{\mathrm{a}}$ allele frequency $=.022$ $\pm .008$

$L u^{\mathrm{a}}$ and $K$ seem to be absent from, or at most very rare among, the Japanese and the Ainu (Nakajuma, 1961; Nakajima et al., 1962). It is not surprising therefore that all 159 samples were $\mathrm{Lu}(\mathrm{a}-)$ and $\mathrm{K}(-)$.

Serum Factors (other than $\mathrm{Gm}$ and Inv): The data for the $\mathrm{Hp}$ and $\mathrm{Gc}$ polymorphisms are presented in Table 7.

$H p^{1}$ occurs with a frequency of about .10 among the Ainu and about .25 among the Japanese (Mourant et al., 1976). The frequency of .181 for $H p^{1}$ among the Matagi is about midway between these values, and is consistent with a postulate of some Ainu admixture. It is, of course, consistent with sampling error and /or drift.

The Gc allele frequencies are essentially identical among the Japanese and Ainu, with $G c^{1}$ equal to about .75 (Mourant et al., 1976). The value of .610 for $G c^{1}$ among the Matagi is lower than that in either of the former two populations and is probably due to chance variation.

The transferrin phenotype of one sample was $\mathrm{B}_{1} \mathrm{C}$ and of another $\mathrm{B}_{2} \mathrm{C}$. The remaining 157 samples were $\mathrm{Tf} C$. Since Tf variants are rare, these data are of no use for classifying populations.

Enzyme Polymorphisms: The data for the enzyme systems showing polymorphism among the Matagi are presented in Table 8. None of the systems is useful for distinguishing Ainu and Japanese, because they have essentially the same frequencies in the two populations (Ap and PGD) or there are no data available for comparison (EsD, $\mathrm{PGM}_{1}$ and GPT).

The PHI, PGK, and AK systems showed no variants, and there was only one variant (3-1) in the GOT system, hence these systems like those mentioned above, do not provide any information concerning the classification of the Matagi.

\section{DISCUSSION}

The Gm data clearly exclude any origin of the Matagi other than Mongoloid (see Johnson et al., 1977 for a review of the Gm data among races) and therefore they exclude the Ainu as the ancestors of the Matagi. The reputed similarities between the Matagi and Ainu cultures clearly have nothing to do with a common biological ancestry. These similarities probably have been acquired in the same way that 
American cultural patterns are acquired by Europeans or Japanese who live in the U.S. If this is correct, it implies that the Ainu and Matagi were sympatric at one time and provides evidence that the Ainu did occupy at least a portion of Honshu in the past, as has been speculated by anthropologists on other grounds.

The $\mathrm{Gm}$ haplotype arrays of the Japanese and the Matagi are identical and their frequencies are very similar, i.e. the same within statistical limits. These data, supported by the data for the blood group and the remaining serum polymorphisms, indicate that the Matagi have descended from Japanese ancestry.

The unusual $\mathrm{Gm}$ haplotype apparently present in a father and daughter i.e., one that produces only $\mathrm{Gm}$ (26) on the $\gamma^{3}$ heavy chain of $\mathrm{IgG}$, is worthy of more extensive study and we shall continue to try to obtain a donation of sufficient blood to permit such a study. The data for the family with this haplotype (Table 5) indicate that great caution should be exercised in using Gm data for paternity tests.

Acknowledgments We are grateful to Mr. Tadashi Nishine and to Mr. Genji Sato, leaders of the Matagi, for their splendid cooperation and also indebted to Mr. Kiyoshi Matsui for his excellent technical assistance.

This project was supported in part by grant Gm07214 from the U.S. National Institute of Health.

\section{REFERENCES}

Abe, T. 1965. Studies on the Gm and Inv factors in Japanese individuais and families. Keio J. of Med. 14: 85-89.

Encyclopedia of the World. Heibonsha, Tokyo.

Giblett, E.R. 1969. Genetic Markers in Human Blood. F.A. Davis Co., Phila., Pa.

Grubb, R. 1970. The Genetic Markers of Human Immunoglobulins. Springer-Verlag, New York.

Johnson, W.E., Kohn, P.H. and Steinberg, A.G. 1977. Population genetics of the human allotypes Gm, Inv, and A2m. Clin. Immunol. and Immunopath. 7: 97-113.

Kita, T. 1932. Studies of the Sanmin Matagi. Nihon Rekishi Chiri Gakkai, Tokyo 59: 592-605.

Kurczynski, T.W. and Steinberg, A.G. 1967. A general program for maximum likelihood estimatior of gene frequencies. Am. J. Human Genet. 19: 178-179.

Mårtensson, L., van Loghem, E., Matsumoto, H. and Nielsen, J. 1966. Gm(s) and Gm(t): genetic determinants of human $\gamma$-globulin. Vox Sang. 11: 393-418.

Matsumoto, H. and Miyazaki, T. 1972. Gm and Inv allotypes of the Ainu in Hidaka area, Hokkaido. Jap. J. Human Genet. 17: 20-26.

Matsumoto, H. and Takatsuki, K. 1968a. Gm factors in Japan: population and family studies. Jap. J. Human Genet. 13: 10-19.

Matsumoto, H. and Takatsuki, K. 1968b. Studies on the Gm factors of Japanese population and families. Jap. J. Legal Med. 22: 635-642.

Misawa, S. and Hayashida, Y. 1972. On the blood groups of the Ainu in Hidaka, Hokkaido. The 56th Conf. of the Medico-Legal Soci. of Japan. Abstract.

Mourant, A.E. 1954. The Distribution of the Human Blood Groups. Charles C. Thomas, Springfield, Illinois.

Mourant, A.E., Kopec, A.C. and Domaniewska, K. 1976. The Distribution of the Human Blood Groups and Other Polymorphisms. Oxford Univ. Press.

Muto, T. 1970. Akita Matagi Kikigaki. Jyomin Bunka Sosho. Vol. 4, Keiyu-sha, Yokyo.

Nakajima, H. 1961. On the distribution of the MNSs, Kell, Duffy, Kidd, and Rh blorid groups among the Japanese. Jap. J. Legal Med. 15: 319-325. 
Nakajima, H., Ikemoto, S. and Furunata, T. 1962. The Lutheran $\left(\mathrm{Lu}^{a}\right)$ blood groups among the Japanese. Proc. Japan Acad. 38: 690-692.

Schanfield, M.S., Gershowitz, H. and Ohkura, K. 1972. Studies on the immunoglobulin allotypes of Asiatic populations. IV Gm and Inv allotypes in three Japanese prefectures and Okinawa. Hum. Hered. 22: 496-502.

Steinberg, A.G. 1962. Progress in the study of genetically determined human gamma globulin types (the Gm and Inv groups). Progress in Med. Genet. 2: 1-33.

Steinberg, A.G. and Matsumoto, H. 1964. Studies on the Gm, Inv, Hp and Tf serum factors of Japanese population and families. Human Biol. 36(2): 77-85.

Steinberg, A.G. 1966. Gm and Inv studies of a Hokkaido populations: evidence for a $\mathrm{Gm}^{2}$ allele in the Ainu. Am. J. Hum. Genet. 18: 459-466.

Steinberg, A.G. 1974. The Gm and Inv immunoglobulin allotypes in Indian populations: A review. Proc. 1st Conf. Ind. Soc. Human Genet. Human Population Genetics in India. 1:112-126.

Steinberg, A.G. 1977. A human antibody to $\mathrm{Gm}$ (26): An antigen usually present on the $\gamma^{3}$ chain of IgG when Gm (15) is absent. Vox Sang., in press.

Steinberg, A.G. and Goldblum, R. 1965. A genetic study of the antigens associated with the Gm (b) factor of human gamma globulin. Am. J. Hum. Genet. 17: 133-147.

Steinberg, A.G. and Kageyama, S. 1970. Further data on the Gm and Inv allotypes of the Ainu: confirmation of the presence of a $\mathrm{Gm}^{1,17,21}$ phenogroup. Am. J. Hum. Genet. 22: 319-325.

Ueno, N. and Yokoyama, M. 1964. Population study of gamma globulin types in Japanese. Zeitschrift für Immunitäts und Allergic Forschung. 127: 58-63.

Ueno, S. 1975. Further studies on the inheritance of $\mathrm{Gm}(\mathrm{m})$ in Japanese families. Jap. J. Human Genet. 19: 317-323.

van Loghem, E. and Grobbelaar, B.G. 1971. A new genetic markers of Ig G3 immunoglobulins. Vox Sang. 21: 405-410.

van Loghem, E. and Mårtensson, L. 1967. Genetic (Gm) determinants of the $\gamma 2 \mathrm{c}$ (Vi) subclass of human IgG immunoglobulins. Vox Sang. 13: 369-392.

van Loghem, E., Natvig, J.B. and Matsumoto, H. 1970. Genetic markers of immunoglobulins in Japanese families. Am. J. Hum. Genet. 33: 351-359. 